\title{
Competent Treatment of a Hypertension in Russia
}

\author{
Dmitrieva Elena Germanovna* \\ Department Of clinical Pharmacist, Pharmaceutical Clinic, Russia \\ *Corresponding author: Dmitrieva Elena Germanovna, clinical Pharmacist, Pharmaceutical Clinic, town of Ivanovo, Russia \\ Submission: September 01, 2017; Published: November 13, 2017
}

\section{Introuction}

Cardiovascular diseases give death rate all over the world, therefore it is necessary to develop criteria of competent treatment of this disease. For today in Russia the diagnosis of hypertensive illness is put only on one measurement of a tonometer, that obviously insufficiently. Medicines from different groups of preparations steal up, but they only reduce arterial pressure, not eliminating true of an original cause of its occurrence at each concrete patient. Thus patients often leave in-home, not hospitalising in clinics that worsens forecasts of treatment and cured. For today, as not the indifferent person having an active civic stand and the expert, I regard such facts, as a genocide. Elderly patients have the right to live qualitatively, considering, that this illness amazes also the young.

Pressure measurement on Korotkov's method has become outdated for a long time also doctors, and even medical sisters measure pressure not truly. Besides, all tonometers, except device Riva-Rochi often deform figures. In Russia sale of tonometers gives profitable business for businessmen from pharmacy, but harms to patients. And from preparations from pressure often there is an accustoming (lekomania), resistance of treatment (not efficiency), ricochets (the facts of dangerous lifting of pressure).

\section{The reasons of lifting of arterial pressure}
a. stress
b. cerebral an atherosclerosis or cardioscleroses
c. genetic and got dislipidemii
d. patologia a climax at women
e. anomalii valves of heart and vessels
f. veins insufficiency
g. metabolic a syndrome
h. drug yatropatii - hormones of a bark of adrenal glands, oral contraceptives, psychotracks
i. endocrine diseases (illness Kushing'a, a diabetes).
j. disease kidneys connected with an ischemia of kidneys.
k. apnoe a dream.

\begin{abstract}
l. lunge a hypertensia
m. big volume of the general blood circulation. Here helps to bleed blood, but this method does not practise Russia almost though, it rescues many lives.

n. genetic blood diseases (insufficiency enzimes).

\section{The molecular mechanism of development of different forms of a hypertensia}

As the Clinical Pharmacist I have found original causes of occurrence of a hypertensia. It is oxygen insufficiency (Dmitrieva E.G., 1994) Deficiency of oxygen is accompanied by decrease resintez various Macroergs's first of all in mitochondrii, that leads to occurrence of deficiency of these connections in cages and intercellular structures so, it is characterised by a lack of power supply of various metabolic, structural and physiological processes of an organism (V.A.Frolov with co-authors, 2009г.). Thus decreases not only oxidising phosphorilation, but also free oxidation (owing to what decrease the basic exchange, Heatprodation and other functions), become more active anaerobic processes, collect non Warmly oxidized metabolits in organism environments.

Especially often at diseases of lungs (апноэ a dream and an infection). Is available both Hypoxia pregnant women and Hypoxia a fruit. Original causes also a lack enzymes antioxidants, as a lack a lack регуляторных connections of the human body. For example, a lack endogenic sodium, calcium, surplus kalii. Paratireoid hypertensive the factor dependent on calcium, by means of functioning Ca2 +- АТФазы. The ionic pomp which deduces the ionised calcium in intercellular spaces, represents connected with calmodulin's Ca +-AtFazu. It is abnormal low activity of isoforms CaAtFazy - the weighty reason of an arterial hypertensia. At children be frequent hypertension original causes can - vaccines, after all they influence a vascular wall. Thus, the original cause will be infectious character. In infections I am engaged many years, and has revealed such terrible law. In detail I describe this mechanism in the books which need to be published.

In regulation of a vascular tone is of great importance mediators nervous excitation, both in the central nervous system, and in all links of transfer of nervous impulses to periphery to vessels. Major importance have, first of all, Noradrenaline and 
Serotonine. Their accumulation in the central nervous system is the important factor supporting a condition of raised excitation of higher regular of the vascular centres that is accompanied by increase of a tone of sympathetic department of nervous system. Impulses from the sympathetic centres are transferred by difficult mechanisms. Ways on sympathetic nervous fibres, by excitation transfer on preganglionar to nervous fibres to adrenal glands with the subsequent allocation Katecholaninas, by excitation of a hypophysis and Hypotalamus with the subsequent allocation in blood Vasopressin's. Secretion growth arginin-vazopressina as an element of pathogenic stress, and the activation consequence renin-angiotenzine systems is a link patogenez hypertensia. All has put in sinapsis. There it is necessary to search for a pathology. It is necessary to develop algorithm of definition in clinical practice and to define at patients that it is competent preventive and to treat any form of a hypertensia

\section{Recommendations about laboratory methods of research}

a) Blood biochemistry - a parity of kalija/sodium, calcium/ phosphorus, calcium and magnesium that in Russia have practically ceased to do. It gives not true treatment, and treatment complications because is frequent instead of decrease kalii, there is its increase. It occurs from uncontrolled reception diurethics, that is inadmissible. Doctors often appoint Asparcam or Panangine, that is inadmissible in the given clinical situation.

b) Circulating and-or in a wall neurogormons (katecholamines, vasopressine, acetylcholine, endoteline, bradicinine, histamine, angiotensinogene and others); Histamin reactions observed, but in Russia by doctors of official medicine it is not considered.

c) Survey of the ophthalmologist - the review of arteries and veins of a retina of eyes, measurement of intraocular pressure. It gives a clear picture of conditions of vessels of all human body

\section{The scheme of competent treatment}

For preventive maintenance of an ischemia of a brain antioxidants - Mexidol (Mexiprime) - on 2ml intravenously on a physiological solution - to 20 injections - 2-3 times a year. This treatment reduces quantity of heart attacks and strokes essentially.

Cytoprotectors - Preductal - on 20mg 2 times a day after meal, a course - till 3 months 2 times year, This treatment are warned by decrease in endocellular maintenance ATF that reduces the phenomena hypoxia a myocardium. Thus membranes of ionic channels kalium and sodium normally function and the cellular homeostasis remains.

Vincamine (Vincanor, Oxibral) - treatment of a hypertensia cerebral genes's for the patients who do not have in the anamnesis diseases of heart. It is resolved in Russia only, as a substance. Vincamine accept mouth, irrespective of food intake time, a unitary dosage of 10-40mg frequency rate of reception 3 times a day. In case of need dose 4 times a day increase to $40 \mathrm{mg}$ a maximum. Course of treatment 1 month, further is passed to supporting dosage by of $20 \mathrm{mg} 1$ or 2 times a day. Course of treatment is 2 months. In pediatrics to children from 6 years use doses of $15 \mathrm{mg}$ a day, divided on 3 receptions. The course lasts 2 months. There are ampoules Oxibral, but they are appointed to elderly patients (doses I describe in the author's book in detail).

It is necessary to select hypertensia treatment on a venous channel, instead of on arterial as it do in Russia more often. Usually at venous disgemia there are hypostases on the person. For this purpose approach Veinotonics. Such as, Detrolex, Veinorutone, Troxevasine and others. Detralex it is shown for the patients having an intracranial hypertensia, others Veinotonics can be appointed for the persons having problems with varicoz of vessels of feet. If to appoint in this situation the preparations operating on an arterial channel it aggravates venous insufficiency. Especially it occurs from preparations of the central action (moxonidine, magnesia). In Russia these preparations of very bad quality. Now Anavenol to Russia it is not delivered, though, the preparation very much approaches for women. The substances received from an ergot are included in structure Anavenola, a horse-chestnut (esculine) and mints odorous (rutozid). The national medicine applies all these plants to treatment of diseases of veins. The substances possessing active medicinal action, are mixed in Anavenol with auxiliary components (corn starch, lactose, etc.). All components which are a part of a preparation, improve blood circulation in small vessels, especially in vessels of feet. Dihydroergocristine expands small arteriols, raises elasticity of venous walls. Esculine and Rutozid render on vessels anti-inflammatory and against a hypostasis action, reduce their permeability. Raised bottom pressure not always should be treated diuretics. More often, inspections neurologic neurophysiology are necessary. So the intracranial hypertensia is often shown. Otherwise, diuretics it is possible to receive parastesis and to grow dumb hands and feet, up to artrosis joints because of excessive downloading of a liquid from a backbone and joints. Such cases observed.

Patients began to accept capsules of biologically active additives - a hawthorn and leaves of red grapes for treatment of veins. It is used capsules of a hawthorn and Aronia black fruits, but it is shown the patients having aritmii and dislipidemii, and also for treatment meteopatii when pressure raises before weather conditions. It cannot be treated antihipertensive therapy. So doctors force down adaptation of an organism to environment conditions that is inadmissible.

I develop a preparation - drops of an extract from the Rhododendron Caucasian. Steal up to everyone individually. The preparation is not registered till now in Russia though, can rescue many lives. The preparation of unique total diphasic action, reduces pressure to norm and holds it. By the way, the preparation cleans oxygen insufficiency in a human body. Tests such have been made by me as early as more many years back.

At a pathological climax when an estrogen there is more than progesterone, it is necessary to appoint preparations Progestines. Before appointment it is necessary to do analyses of biochemistry 
of blood on hormones necessarily. These doses too steal up individually.

Arginine - the aid donor of nitrogen - capsules on 500mg. This amino acid in sunflower seeds and nuts (almonds, a peanut, cedar and walnuts pumpkin) contains. In the pumpkin contains - 5,343 grammes, it is more than all. Daily requirement - 6,1 grammes. In pork, a hen (fillet), an egg, a liver, cottage cheese - from 600 to 1400mg. Other products containing this amino acid - peas, corn, raisin, porridge, gelatin, snails, anchovies, a tuna, shrimps, crabs, a crude fillet of a salmon, white fish, a flounder.

\section{Conclusion}

So, I hope, that competent treatment will take place in Russia by means of Clinical Pharmacists. 